УДК 004.89

\title{
АНАЛІЗ ПРОСТОРОВОЇ ЖОРСТКОСТІ СКРІПЛЕНЬ ДО
}

Інж. Ю.Л. Тулей

\section{АНАЛИЗ ПРОСТРАНСТВЕННОЙ ЖЕСТКОСТИ СКРЕПЛЕНИЯ ДО}

Инж. Ю.Л. Тулей

ANALYSIS OF SPATIAL INFLEXIBILITY OF CLAMPING DO

\author{
Ing. Tuley J.L.
}

У статті виконано аналіз роботи проміжних скріплень типу ДО в процесі експлуатації під дією вертикальних і горизонтальних поперечних сил.

Отримано математичні моделі вертикальної $і$ горизонтальної поперечної жорсткостей, а також жорсткості рейки при крученні.

При визначенні найбільш точних значень жорсткостей скріплень ДО визначено необхідність враховувати значення коефіцієнтів постелі підкладки та жорсткість костилів при їх поперечному віджиманні.

Ключові слова: жорсткість скріплень, коефіцієнт постелі підкладки, скріплення ДО.

В статье выполнен анализ работы промежуточных скреплений типа ДО в прочессе эксплуатации под действием вертикальных и горизонтальных поперечных сил.

Получены математические модели вертикальной и горизонтальной поперечной жесткостей, а также жесткости рельса при кручении.

При определении наиболее точных значений жесткостей скреплений ДО определена необходимость учитывать значение коэффициентов постели подкладки и жесткость костылей при их поперечном отжатии.

Ключевые слова: жесткость скреплений, коэффициент постели подкладки, скрепления ДО.

In the article the analysis of work of the intermediate clamping of type is executed DO in the process of exploitation, under action of transversal forces vertical and horizontal.

The mathematical models of transversal vertical, horizontal are got inflexibilities, and also inflexibility of rail at twisting.

At determination of vertical inflexibility of clamping $D O$, for the receipt of more exact numeral meaning, the coefficient of bed of podkladki, which takes into account resilient properties of tree under action of loading, was entered.

A calculation chart for determination of horizontal transversal inflexibility is resulted. This chart is used for determination of horizontal transversal force which causes only the horizontal moving of rail without his twisting, and also between the sole of rail, by podkladkoyu and crutches gaps are absent.

For the terms of display and forming of horizontal transversal inflexibility of clamping DO expressions, which I take into account clamping operating on a knot forces vertical and horizontal, coefficient of friction of podkladki on a railroad tie and inflexibility of crutch, at his transversal wringing out are resulted.

At determination of inflexibility of rail at twisting under action of vertical force, which causes crumpling and compression of tree on a size which causes resilient resistance, intensity of this force as equalization of reaction was represented.

Keywords: inflexibility of clamping, coefficient of bed of podkladki, clamping DO.

Вступ. Скріплення типу ДО є найпоширенішим типом проміжного скріплення для конструкції ланкової колії на дерев'яних шпалах, протяжність якої на окремих 
залізницях сягає $35 \%$. Така конструкція застосовується, у першу чергу, У кривих малих радіусів.

Українським залізницям необхідно витрачати щорічно на заміну дефектних рейок $\mathrm{i}$ ремонти колії 100 тис. т рейок. 3 дефектних рейок, що вилучаються з колії, більш ніж $20 \%$ припадає на рейки, у яких боковий знос головки перевищив допустимий за умов безпеки руху поїздів. Рейки 3 такими дефектами вилучаються практично тільки 3 кривих ділянок, радіуси яких менш ніж 400 м, між тим загальна протяжність таких ділянок складає більше $2,5 \%$. Безумовно, інтенсивний боковий знос рейок викликається значною кількістю причин. Для вирішення цієї проблеми важливо знати кількісну оцінку кожної 3 причин, які передбачаються. Такі дослідження можливо виконувати тільки за допомогою чисельних методів. Але чисельний аналіз неможливий без математичного моделювання, у тому числі роботи скріплень типу ДО під дією просторових сил.

Аналіз останніх досліджень i публікацій. Значний внесок у вирішення питань взаємодії рухомого складу та колії належить науковим школам, які сформували Ангелейко B.I. [1], Даниленко E.I. [9], В.В. Рибкін [10], В.А. Лазарян [4] та М.А. Фрішман [3], М.Ф. Веріго [2], С.П. Першин [8], Яковлєва В.Ф. [7], Коган О.Я. $[5,6]$.
Слід зазначити, що в цих дослідженнях використовувалася загальна розрахункова схема у вигляді балки на суцільній пружній основі. Ця схема передбачає постійність пружних дисипативних характеристик підрейкової основи. Однак аналіз, зроблений у роботі [11], показав, що така схема для деяких умов експлуатації надмірно ідеалізує колію та $\dddot{11}$ технічний стан.

Визначення мети та задач дослідження. Метою даної статті є аналіз роботи проміжних скріплень типу ДО під дією вертикальних і горизонтальних поперечних сил та отримання математичних моделей жорсткостей цього скріплення.

Основна частина. Вертикальна жорсткість скріплень ДО

При дії вертикального навантаження $R_{y}$ на скріплення ДО відбувається зминання $\mathrm{i}$ стиснення упоперек волокон деревини шпали під підкладкою. Приймаючи пружний опір деревини рівномірно розподіленим за площею підкладки (рис. 1), можна записати, кН,

$$
R_{y}=\omega_{n} \cdot q_{\text {nod }},
$$

де $\omega_{n}$ - площа підрейкової підкладки скріп-

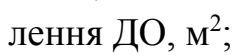

$q_{\text {под }}$ - розподілений пружний опір деревини, $\mathrm{\kappa H} / \mathrm{M}^{2}$.

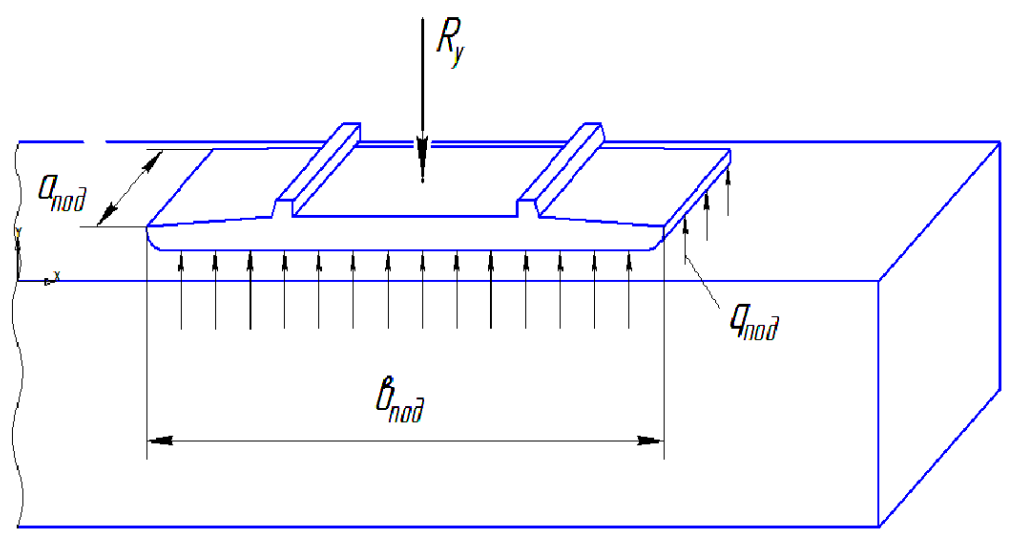

Рис. 1. Розрахункова схема для визначення вертикальної жорсткості скріплення ДО

Введемо розрахункову величину $C_{\text {nод }}$ коефіцієнт постелі підкладки, який характеризує властивості деревини при іiі зминанні i стисненні упоперек волокон i чисельно дорівнює навантаженню, яке прикладено до одиничної площі деревини i викличе одиночну пружну деформацію, кН/ $\mathrm{M}^{3}$. Тоді 


$$
q_{\text {nод }}=C_{\text {nод }} \cdot y_{c \kappa p}^{c p}
$$

де $y_{c \kappa p}^{c p}-$ середнє значення вертикальної пружної деформації в скріпленні ДО, м.

Металева підкладка повинна розглядатися як пластина, що розташована на пружній підставі і працює під дією вертикальних сил. Прогинання ऑii в підрейковому перетині виявляються більшими, ніж це було б у разі жорсткого штампа. Проте при визначених пружних властивостях деревини не під штампом, а під металевою підкладкою скріплення в результаті експериментальних робіт можна отримати значення $C_{\text {под }}$ з урахуванням жорсткості підкладки.
3 урахуванням висловленого, вертикальну жорсткість скріплення ДО можна визначати як

$$
C_{y c \kappa}=\omega_{n} \cdot C_{\text {nод }}
$$

де $w_{n}$ - площа підкладки, $\mathbf{M}^{2}$.

Горизонтальна поперечна жорсткість скріплення ДО

Розрахункова схема для визначення горизонтальної поперечної жорсткості наведена на рис. 2. Ця схема застосовна за таких умов: дія горизонтальної поперечної сили $R_{z}$ викликає тільки горизонтальне переміщення рейки без ii кручення; між підошвою рейки, підкладкою і костилями зазори відсутні.

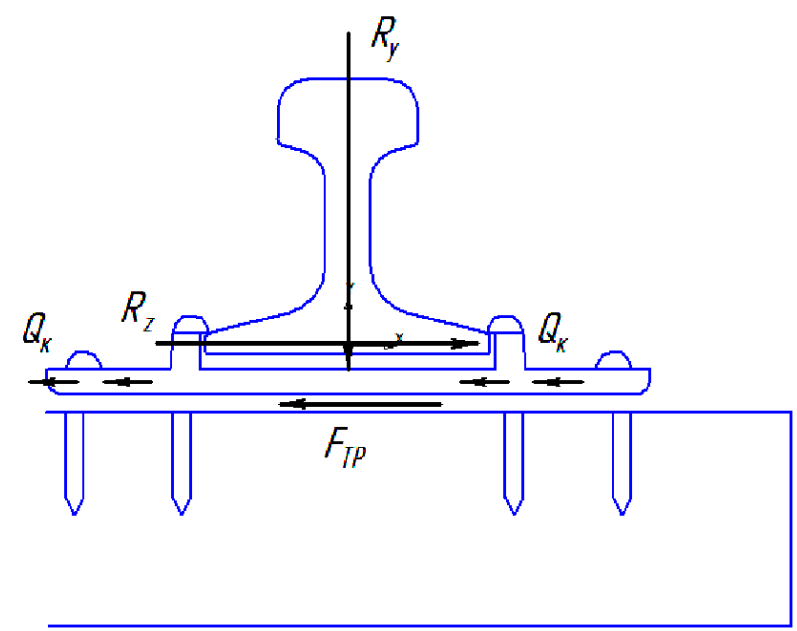

Рис. 2. Схема завантаження вузла скріплення ДО поперечним навантаженням вигляд

Умова рівноваги у вузлі скріплення має

$$
R_{z}=F_{m p}+m Q_{\kappa}
$$

де $F_{m p}$ - сила тертя підкладки по шпалі;

$Q_{\kappa}$ - опір одного костиля поперечному віджиманню;

$m$ - кількість основних і обшивних костилів у вузлі скріплення.

До подолання сили тертя $F_{m p}$ горизонтальних поперечних деформацій у вузлі скріплення не відбувається.

Тоді умови прояву i формування горизонтальної поперечної жорсткості скріплення ДО можна представити такими виразами:

$$
\left.\begin{array}{c}
-n p u R_{z}<f_{\text {nод }} \cdot R_{y} \\
C_{z}=\infty \\
-n p u R_{z} \geq f_{\text {nоd }} \cdot R_{y} \\
C_{z}=m \cdot C_{\kappa}(\kappa H / M)
\end{array}\right\}
$$

де $R_{y}$ i $R_{z}$ - діючі на вузол скріплення вертикальна і горизонтальна поперечні сили, кН;

$f_{\text {nод }}$ - коефіцієнт тертя підкладки по шпалі;

$C_{\kappa}$ - жорсткість костиля при його поперечному віджиманні, кН/м.

Жорсткість скріплення ДО при крученні рейки

Скріплення ДО, як і скріплення КБ, працює на кручення, будучи одночасно завантаженим вертикальною силою $R_{y}$. Ця сила створює 
зминання і стиснення деревини на величину $y$, викликаючи пружній опір, інтенсивність якого можна представити у вигляді розподіленої по ширині підкладки $\boldsymbol{B}_{\text {под }}$ реакції (рис. 1):

$$
q_{n}=\frac{R_{y}}{B_{\text {по }}}=\frac{\omega_{n} \cdot C_{n o \partial}}{B_{\text {nод }}} \cdot y
$$

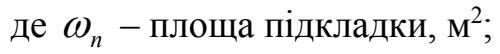

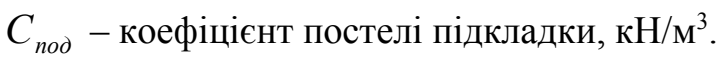

Під дією крутного моменту $M_{\kappa p}$ кромки підошви підкладки одержують додаткові деформації $\Delta y_{1}$ i $\Delta y_{2}$ (рис. 3).

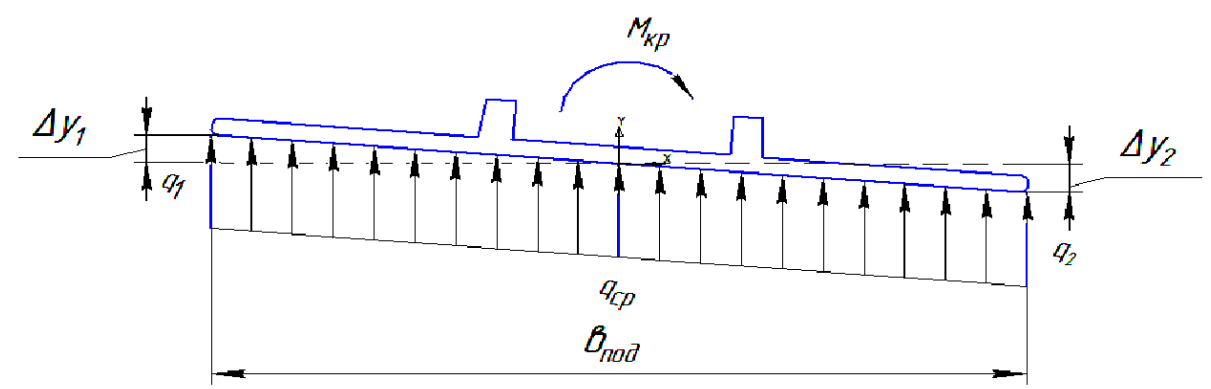

Рис. 3. Схема навантаження вузла скріплення ДО крутним моментом

При цьому величини $\Delta y_{1}$ i $\Delta y_{2}$ значно менше від величини деформації $y_{1}$, викликаної вертикальним навантаженням $R_{y}$ [9]. Таким чином, розглядаючи умову рівноваги моментів у вузлі скріплення ДО, зміною сил притиснення основних i обшивних костилів можна нехтувати.

Умова рівноваги зовнішнього крутного моменту $M_{\kappa p}$ i моменту нерівномірно розподіленої реакції деревини шпали відносно центра повороту перетину рейки матиме вигляд

$$
M_{\kappa p}+\left(q_{1}+q_{c p}\right) \frac{\beta_{n o \partial}^{2}}{16}-\left(q_{c p}+q_{2}\right) \frac{\beta_{n o \partial}^{2}}{16}=0
$$

Або інакше

$$
M_{\kappa p}=\left(q_{2}-q_{1}\right) \frac{\beta_{n o \partial}^{2}}{16} .
$$

Інтенсивності розподіленого навантаження $q_{1}$ i $q_{2}$ представимо як

$$
q_{1}=\left(y-\Delta y_{1}\right) \frac{\omega_{n} \cdot C_{n o \partial}}{8_{n o \partial}}
$$

$$
q_{2}=\left(y+\Delta y_{2}\right) \frac{\omega_{n} \cdot C_{n o d}}{6_{\text {под }}}
$$

Тоді вираз (3) матиме вигляд

$$
M_{\kappa p}=\left(\frac{\Delta y_{2}+\Delta y_{1}}{B_{\text {под }}}\right) \omega_{n} \cdot C_{n о д} \frac{\boldsymbol{B}_{\text {nод }}^{2}}{16}
$$

Враховуючи, що 3 причини малості кута закручування $\varphi=\frac{\Delta y_{2}+\Delta y_{1}}{\beta_{\text {под }}}$, можна одержати залежність жорсткості скріплення ДО при крученні від коефіцієнта постелі підкладки, кН/рад,

$$
C_{\varphi}=\omega_{n} \cdot C_{n o \partial} \cdot \frac{B_{n o \partial}^{2}}{16} .
$$

Висновки. Таким чином, для визначення значень жорсткостей скріплення ДО і їх змін у процесі експлуатації необхідні значення коефіцієнтів постелі підкладки $C_{\text {под }}$, жорсткість костилів $C_{\kappa}$ при їх поперечному віджиманні.

\section{Список використаних джерел}

1. Ангелейко, В.И. Вывод основных уравнений для расчета рельса в горизонтальной и вертикальной плоскостях [Текст]: монография / В.И. Ангелейко. - Харьков: ХИИТ, 1958. - 38 с.

2. Вериго, М.Ф. Вертикальные силы, действующие на путь при прохождении подвижного состава [Текст] / М.Ф. Вериго // Труды ВНИИЖТ. - М.: Трансжелдориздат, 1955. - № 97. - С. $25-288$. 
3. Фришман, М.А. Экспериментальные определения жесткостей и неупругих сопротивлений пути [Текст] / М.А. Фришман, Л.Я. Воробейчик, Р.С. Липовской // Вестник ЦНИИ МПС. - 1970. № 8. - C. 31-35.

4. Лазарян, В.А. Изгибные колебания кузова полувагона в вертикальной и горизонтальной плоскостях [Текст] / В.А. Лазарян, В.Ф. Ушаков // Труды ДИИТ. - 1967. - № 68. - С. 32-38.

5. Коган, А.Я. Вертикальные динамические силы, действующие на путь [Текст] / А.Я. Коган // Труды ЦИИТ МПС. - М.: Транспорт, 1969. - 206 с.

6. Расчеты железнодорожного пути на вертикальную динамическую нагрузку [Текст] / под. ред. А.Я. Когана // Труды ВНИИЖТ. - 1973. - № 502. - 80 с.

7. Яковлев, В.Ф. Определение расчетных параметров пути в вертикальной и горизонтальной плоскостях с помощью вибромашины [Текст] / В.Ф. Яковлев, И.И. Семенов, В.И. Абросимов // Труды ЛИИЖТа. - Л.: ЛИИЖТ, 1971. - Вып. 326. - С. 66-85.

8. Першин, С.П. Вертикальная жесткость пути и его надежность [Текст] / С.П. Першин // Путь и путевое хозяйство. - 1996. - №8. - С.8-10.

9. Даніленко, Е.І. Сучасні рейкові пружні скріплення і особливості вимог до вітчизняних скріплень на залізобетонних шпалах [Текст] / Е.І. Даніленко, М.Д. Костюк, О.М. Жученко // Транспорт України. - 2002. - № 6. - С. 3-12.

10. Рибкін, В.В. Теоретичні дослідження впливу пружності проміжних рейкових скріплень на деформативну роботу колії [Текст] / В.В. Рибкін, М.Д. Костюк, Н.П. Настечик, М.П. Сисин // Тези LXVI Міжнар. наук.-практ. конф. "Проблеми та перспективи розвитку залізничного транспорту”. Дніпропетровськ, 2006. - № 1. - С. 188.

11. Даренський, О.М. Теоретичні та експериментальні дослідження роботи залізничних колій промислового транспорту [Текст]: монографія / О.М. Даренський. - Харків: УкрДАЗТ, 2011. - 204 с.

Рецензент д-р техн. наук, професор О.М. Даренський

Тулей Юзеф Леонідович, начальник Департаменту колії Укрзалізниці. Тел.: 044-465-03-50.

Tuley Yusef Leonidovich, нead of the Department Ukrzaliznytsia. Tel. 044-465-03-50.

Стаття прийнята 09.11.2015 p. 